\title{
Outcome Comparison Between Pulmonary and Extrapulmonary Acute Respiratory Distress Syndrome in Pediatric Intensive Care Unit
}

\author{
Ni Made Reditya Noviyani, Ida Bagus Gede Suparyatha*, Dyah Kanya Wati, \\ I Nyoman Budi Hartawan
}

Department of Child Health, Faculty of Medicine, Udayana University, Denpasar, Indonesia

Email address:

tyanoviyani13@gmail.com (Ni M. R. Noviyani), ibgsuparyatha@yahoo.com (I. B. G. Suparyatha)

*Corresponding author

\section{To cite this article:}

Ni Made Reditya Noviyani, Ida Bagus Gede Suparyatha, Dyah Kanya Wati, I Nyoman Budi Hartawan. Outcome Comparison Between Pulmonary and Extrapulmonary Acute Respiratory Distress Syndrome in Pediatric Intensive Care Unit. American Journal of Pediatrics. Vol. 6, No. 4, 2020, pp. 442-447. doi: 10.11648/j.ajp.20200604.19

Received: October 9, 2020; Accepted: October 22, 2020; Published: October 30, 2020

\begin{abstract}
Acute respiratory distress syndrome (ARDS) is a lung disease characterized by severe diffuse inflammation and hypoxemia. The cause of ARDS can be pulmonary or extrapulmonary originated. The outcome of pulmonary and extrapulmonary pediatric ARDS are poorly described. The objective of this study was to determine the outcome differences between pulmonary and extrapulmonary pediatric ARDS. A retrospective study was carried out in 60 patients who admitted to the Pediatric Intensive Care Unit (PICU), Sanglah Hospital, between January 2018 until December 2019. All children aged 0-18 years old diagnosed with ARDS according to Pediatric Acute Lung Injury Consensus Conference (PALICC) criteria were included in this study. Length of ventilation, ventilator-free days, PICU length of stay, and PICU mortality as the outcome of this study were obtained from medical records. Statistical analysis was done using Chi-square and Mann-Whitney test. Most of the patients were supported by invasive ventilation with the severity of ARDS was mild to moderate. The underlying disease of pulmonary ARDS (ARDSp) was pneumonia (100\%), whereas in extrapulmonary ARDS (ARDSexp) was sepsis $(100 \%)$. Analysis of outcome showed significant difference in mortality $(33.3 \%$ vs $73.3 \%, \mathrm{p}=0.002)$. The mortality was higher among those in the moderate severity of oxygenation index $(64.5 \%, \mathrm{p}=0.001)$. No significant difference was found in length of ventilation and PICU length of stay. The ventilator-free days in ARDSp was higher (22 days vs 0 days, $p=0.000$ ) compared with the ARDSexp. This study concluded that patients with extrapulmonary ARDS had poorer outcomes (higher mortality and less ventilator-free day) compared with pulmonary ARDS. The severity of ARDS based on the oxygenation index measurement can be used to discriminate mortality.
\end{abstract}

Keywords: Pediatric, Pulmonary and Extrapulmonary ARDS, Outcome

\section{Introduction}

Acute respiratory distress syndrome (ARDS) is a lung disease characterized by severe diffuse inflammation and hypoxemia. ARDS is a heterogeneous syndrome with a complex pathology and mechanism of disease which results in important cause of Pediatric Intensive Care Unit (PICU) admission with significant contribution to morbidity and mortality in children [1-3]. The acute respiratory distress syndrome is characterized by acute onset of fast breathing, breathlessness, hypoxemia, and chest skiagram may show bilateral infiltrates [4]. The Pediatric Acute Lung Injury Consensus Conference (PALICC) was convened to propose specific definitions for pediatric ARDS. The main differences in the PALICC definition are the use of oxygenation index (OI) instead of $\mathrm{PaO} 2 / \mathrm{FiO} 2$, the ability to diagnose pediatric ARDS in the absence of arterial blood gas analysis by using non-invasive measures of hypoxemia based on $\mathrm{SpO} 2$ (oxygen saturation index (OSI)), and less restrictive radiographic criteria [5]. Pediatric ARDS can affect all pediatric age groups, from the neonatal period through adolescence. Evidently, perinatal causes of acute hypoxemia 
are excluded. Symptoms of hypoxemia and radiological changes must occur within 7 days of a known clinical insult. The presence of new infiltrates consistent with the lung parenchymal disease is required for the diagnosis, even if unilateral. The PALICC offered specific patient management recommendations for pediatric ARDS [6, 7].

Prevalence of ARDS in children in the United States, Europe, and Australia is 2-12.8 cases/100.000 people per year It has been estimated that ARDS accounts for $1-4 \%$ of all PICU admissions, $8-10 \%$ patients requiring mechanical ventilation and estimated mortality of $20-75 \%$ despite advances in the management [8-10]. In North America, multicenter study reported that $1-4 \%$ of children undergoing mechanical ventilation had ARDS. In PICU Sanglah Hospital, Bali, acute lung injury and ARDS constituted $18 \%$ of all cases between 2013-2014 [11]. Many studies have revealed that the mortality rate in children suffering from ARDS ranges between $18-27 \%$. Data from Australian study suggested that child mortality due to ARDS is high (35\%). Due to high mortality rates, ARDS remains the ultimate challenge in PICU in terms of management and outcome [12-15].

The pathophysiology of ARDS in children is complex and multifactorial. The cause of ARDS can be pulmonary or extrapulmonary originated. In a comprehensive description of pediatric ARDS, the primary etiologies were pneumonia (35\%), aspiration (15\%), sepsis $(13 \%)$, near-drowning $(9 \%)$, and concomitant cardiac disease $(7 \%)[7,16]$. The pulmonary and extrapulmonary ARDS have different pathophysiology, epidemiology, and radiologic profiles. Pulmonary ARDS results from a direct infective or inflammatory insult to the lung parenchyma leading to disruption of the alveolar epithelium, alterations of the type I and II cells and neutrophils, and filling of the intra-alveolar space with fibrinous exudate and collagen with minimal interstitial edema. Extrapulmonary ARDS results from a systemic insult leading to widespread circulation of inflammatory mediators, pulmonary vascular endothelial damage, increased vascular permeability, and interstitial edema [17-19].

Pulmonary and extrapulmonary pediatric ARDS are poorly described in the literature. A small single-center study reported no difference in mortality in the two subgroups of pediatric ARDS [20, 21]. Conversely, a multicenter analysis in ten multidisciplinary PICUs in Asia showed that patients with extrapulmonary pediatric ARDS were sicker and had poorer clinical outcomes [22]. In the current study, we sought to determine the outcome differences between pulmonary and extrapulmonary pediatric ARDS in PICU Sanglah Hospital.

\section{Methods}

A retrospective study was carried out in patients with diagnosed acute respiratory distress syndrome between January 2018 until December 2019 in the PICU, Sanglah Hospital. We compared the outcome between pulmonary and extrapulmonary ARDS. Cases and medical record number were obtained from a registry of patient in PICU. Medical records were reviewed and the following data include the length of ventilation, ventilator-free days, PICU length of stay, and PICU mortality were collected. This study was approved by the Research Ethics Committee and Institutional.

Subjects were consecutively enrolled until complete the required sample size. After measured by the formula for estimating the sample size, the total minimum sample was 60 patients. The inclusion criteria were all children aged 0-18 years old and diagnosed with acute respiratory distress syndrome according to PALICC definition. The exclusion criteria were incompletely medical record, the patient had major congenital anomalies, and perinatal cause of hypoxemia.

The variables used in PALICC criteria were duration of onset of acute illness to ARDS of less than 7 days, origin of pulmonary edema, any new infiltrate on chest $\mathrm{x}$-ray, and oxygenation defect based on $\mathrm{SpO}_{2}: \mathrm{FiO}_{2}$ (SF) ratio or $\mathrm{PaO}_{2}: \mathrm{FiO}_{2}$ (PF) ratio if on non-invasive mechanical ventilation and oxygenation index (OI) or oxygen saturation index (OSI) if on invasive mechanical ventilation. Length of ventilation defines as the total amount of time spent by the patient using mechanical ventilation. Ventilator-free days define number of days without mechanical ventilation in the first 28 days. Patients requiring ventilation for greater than or equal to 28 days and those who died within 28 days of PICU admission were assigned a ventilator-free day of zero. PICU length of stay defines as the total amount of time spent by the patient from initial diagnosis of acute respiratory distress syndrome until being transferred to a ward. PICU mortality defines as the number of deaths of patients with acute respiratory distress syndrome admitted to the Pediatric Intensive Care Unit.

Collected data were analyzed using SPSS for Windows. Analysis to compare the PICU mortality of pulmonary and extrapulmonary ARDS was using Chi-square test. Length of ventilation, ventilator-free days, and PICU length of stay were analyzed using the Mann-Whitney test. P-values of less than 0.05 was considered statistically significant for data analysis.

\section{Result}

There were 93 children with ARDS admitted in PICU, Sanglah Hospital, from January 2018 until December 2019. We excluded 33 cases which had major congenital anomalies, perinatal cause of hypoxemia, and incomplete medical record. Sixty cases were retained for analysis, which is 30 subjects in each group.

The characteristics of subjects are described in Table 1. The median age of subjects was 2 months for the ARDSp group and 6 months for the ARDSexp group. The median of the interval between onset of illness and symptoms of hypoxemia was 3 days in both groups. The median oxygenation index (OI) in the ARDSexp group was higher compared with the ARDSp group (6.2 vs 4.7). The ARDSexp group received more blood transfusions (73.3\%) and inotropes (93.3\%) compared with the ARDSp group. The underlying disease of ARDSp was 
pneumonia (100\%), whereas in ARDSexp was sepsis (100\%). Most of the patients were supported by invasive ventilation with the severity of ARDS was mild to moderate as described in Table 2.

Table 1. Sample characteristics.

\begin{tabular}{|c|c|c|}
\hline Variable & $\operatorname{ARDSp}(n=30)$ & $\operatorname{ARDSexp}(n=30)$ \\
\hline Age, median (range), months & $2(1-180)$ & $6(1-144)$ \\
\hline \multicolumn{3}{|l|}{ Sex } \\
\hline Male, n (\%) & $20(66.7)$ & $15(50)$ \\
\hline Female, n (\%) & $10(33.3)$ & $15(50)$ \\
\hline Interval between onset of illness and symptoms of hypoxemia, median (range), days & $3(1-7)$ & $3(1-7)$ \\
\hline \multicolumn{3}{|l|}{ Oxygenation } \\
\hline $\mathrm{PO} 2 / \mathrm{FiO}_{2}$ ratio, mean $(\mathrm{SD})$ & $234.2(40.6)$ & $229.3(31)$ \\
\hline Oxygen index, median (range) & $4.7(4-14.7)$ & $6.2(4-14.5)$ \\
\hline Oxygen saturation index, median (range) & $6.2(5-11.9)$ & $7.3(5-12.3)$ \\
\hline \multicolumn{3}{|l|}{ Ventilation } \\
\hline Invasive, $\mathrm{n}(\%)$ & $25(83.3)$ & $27(90)$ \\
\hline Non-invasive, n (\%) & $5(16.7)$ & $3(10)$ \\
\hline PELOD-2 score, median (range) & $3(0-6)$ & $9(7-13)$ \\
\hline Blood culture positivity, n (\%) & $0(0)$ & $1(3.3)$ \\
\hline \multicolumn{3}{|l|}{ Nutritional status } \\
\hline Failure to thrive, $\mathrm{n}(\%)$ & $4(13.3)$ & $5(16.7)$ \\
\hline Well nourished, n (\%) & $12(40)$ & $10(33.3)$ \\
\hline Moderate malnutrition, $\mathrm{n}(\%)$ & $10(33.3)$ & $11(36.7)$ \\
\hline Severe malnutrition, n (\%) & $0(0)$ & $0(0)$ \\
\hline Overweight, $\mathrm{n}(\%)$ & $1(3.3)$ & $3(10)$ \\
\hline Obesity, n (\%) & $3(10)$ & $1(3.3)$ \\
\hline Blood transfussion, $\mathrm{n}(\%)$ & $14(46.7)$ & $22(73.3)$ \\
\hline Inotropes, $\mathrm{n}(\%)$ & $0(0)$ & $28(93.3)$ \\
\hline \multicolumn{3}{|l|}{ Underlying disease } \\
\hline Pneumonia, n (\%) & $30(100)$ & $0(0)$ \\
\hline Sepsis, $\mathrm{n}(\%)$ & $0(0)$ & $30(100)$ \\
\hline
\end{tabular}

Table 2. Severity stratification based on oxygenation.

\begin{tabular}{llc}
\hline Variable & ARDSp (n=25) & ARDSexp (n=27) \\
\hline OI category & $14(56)$ & $14(51.9)$ \\
Mild, n (\%) & $11(44)$ & $13(48.1)$ \\
Moderate, n (\%) & $0(0)$ & $0(0)$ \\
Severe, n (\%) & $14(56)$ & $14(51.9)$ \\
OSI category & $11(44)$ & $13(48.1)$ \\
Mild, n (\%) & $0(0)$ & $0(0)$ \\
Moderate, $\mathrm{n}(\%)$ & & \\
Severe, $\mathrm{n}(\%)$ & & \\
\hline
\end{tabular}

Analysis of outcome showed significant difference in mortality between ARDSp group and ARDSexp group (33.3\% vs $73.3 \%, p=0.002)$. The ventilator-free days in ARDSp group was higher ( 22 days vs 0 days, $\mathrm{p}=0.000$ ) compared with the ARDSexp group. No significant difference was found in length of ventilation and PICU length of stay as shown in Table 3. The mortality was higher among those in moderate severity of oxygenation index $(64.5 \%, \mathrm{p}=0.001)$ as shown in Table 4 . No severe case was found in this study.

Table 3. Comparison of outcome between ARDS groups.

\begin{tabular}{|c|c|c|c|}
\hline Variable & $\operatorname{ARDSp}(n=30)$ & $\operatorname{ARDSexp}(\mathrm{n}=30)$ & $p$ \\
\hline Mortality (\%) & 33.3 & 73.3 & 0.002 \\
\hline Length of ventilation, median (range), days & $6(1-19)$ & $5(1-19)$ & 0.583 \\
\hline PICU length of stay, median (range), days & $9(1-20)$ & $5(1-19)$ & 0.505 \\
\hline Ventilator-free days, median (range), days & $22(0-27)$ & $0(0-25)$ & 0.000 \\
\hline
\end{tabular}

Table 4. Comparison of mortality based on oxygenation index.

\begin{tabular}{llll}
\hline \multirow{2}{*}{ Variable } & \multicolumn{3}{c}{ OI category } \\
\cline { 2 - 3 } & Mild $\mathbf{n = 2 8}$ & Moderate $\mathbf{n}=\mathbf{2 4}$ \\
\hline Mortality (\%) & 35.5 & 64.5 \\
\hline
\end{tabular}




\section{Discussion}

The median age of subjects in our study was 2 months for the ARDSp group and 6 months for the ARDSexp group with the majority of them were male. It is similar to another study showing the incidence of ARDS among patients admitted to the PICU was $2.6 \%$ and the majority of subjects were under 1 year old and male [23].

In this study, the underlying disease in ARDSexp group was sepsis $(100 \%)$, whereas in ARDSp was pneumonia (100\%). A study by Khemani in 2018 found pneumonia or lower respiratory tract infection and sepsis were the most common ARDS risk factors. The larger study reported a prevalence of ARDSexp was $40 \%$ with the majority due to sepsis (98.8\%). This is consistent with a study by Gan in 2018 that the most common extrapulmonary risk factor of ARDS was sepsis $(82.9 \%)$ [21, 22, 24].

We compared the outcome of ARDSp and ARDSexp. Mortality of patients with ARDSexp was higher as those with ARDSp (73.3\% vs $33.3 \%, p=0.002)$. A study by Gan in 2018 found similar results in our study. The PICU mortality of children with ARDSexp was twice as high as those with ARDSp (48.8\% vs 24.8\%) [22]. Examine data from mixed cohorts of ARDS across the world, higher mortality in children with extrapulmonary etiologies was reported, compared with those with pulmonary etiologies $(58-80 \%$ vs $28-60 \%$ ) [2, 8, 25]. In a meta-analysis involving 3,283 pediatric ARDS patients, post hoc analysis demonstrated that extrapulmonary etiology had an odds ratio (OR) of mortality of 3.29 [26]. Patients with ARDSexp had higher Pediatric Logistic Organ Dysfunction (PELOD)-2 score (9 vs 3) as those with ARDSp. It describes the severity of organ dysfunction in patients with ARDSexp. A secondary study of a prospective pediatric sedation trial also demonstrated the association between ARDSexp and concurrent multiple organ dysfunction [27].

The pulmonary and extrapulmonary ARDS have different pathophysiology. In ARDSp, the prevalent damage in early stage is likely intra-alveolar, whereas in ARDSexp is interstitial edema with greater inflammatory agents in the bloodstream [17, 21]. In this inflammatory cascade, the release of chemokines by local antigen presenting cells and endothelial cells, leading to migration of activated neutrophils to the lungs and release of cytokines. These mechanisms lead to an increase in lung endothelial permeability and immune activation, which can propagate the cell damage. In a study by Zinter in 2017, there was a significant association between mortality and elevated plasma cytokines in children with ARDS. These cytokines were also associated with ARDS illness severity (including OI), intensive care unit morbidity (including PELOD score), and biochemical evidence of endothelial injury [28-30].

Patients with ARDSexp also had less ventilator free days compared with ARDSp (0 vs 22 days, $p=0.000)$. Ventilator-free days in patients with ARDS who died within 28 days of PICU admission were assigned a ventilator-free day of zero. Mortality of patients with ARDSexp was higher as those with ARDSp. It implies in less ventilator free days of ARDSexp. A study by Gan in 2018 found similar results in our study. Ventilator free days in patient with ARDSexp was lower compared with ARDSp ( 2 days vs 19 days, $p=0.001$ ) [22]. In terms of respiratory mechanics, patients with ARDSexp have reduced chest wall compliance and increased chest wall elastance $[31,32]$. The elastance of the chest wall was more than twofold higher in ARDSexp than in ARDSp, indicating a stiffer chest wall. The increase in elastance of the chest wall was related to an increase in the intra-abdominal pressure, which was threefold greater in ARDSexp. The resistance of the chest wall was also elevated in ARDSexp. It is significantly correlated to intra-abdominal pressure, suggesting that intra-abdominal pressure can affect the viscoelastic properties of the thoracoabdominal region [17].

The PALICC definition recommends the use of an oxygenation index to determine hypoxemia severity, rather than the PF ratio as in the Berlin definition. A study by Khemani in 2018 found that severity groups based on an oxygenation index or oxygen saturation index measurements generally outperformed those based on PF or SF ratios to discriminate mortality [24]. In our study, most of the patients were supported by invasive ventilation with the severity of ARDS was mild to moderate and no severe case was found. The median of oxygenation index (OI) in the ARDSexp group was higher compared with the ARDSp group (6.2 vs 4.7). The mortality was significantly higher among those in moderate severity of oxygenation index $(64.5 \%, \mathrm{p}=0.001)$.

There are some limitations of this study. The retrospective data of this study precludes us from making causal associations, introduces bias in case selection, and potential misclassification into ARDSp and ARDSexp groups. A number of these patients had to be excluded to avoid bias due to misclassification. A few patients in certain categories of ARDS could limit generalizability. The consequence of the small sample size was the lack of statistical significance in outcomes between ARDSp and ARDSexp groups.

\section{Conclusion}

Patients with extrapulmonary pediatric ARDS had poorer outcomes (higher mortality and less ventilator-free days) compared with pulmonary pediatric ARDS. The severity of ARDS based on the oxygenation index measurement can be used to discriminate mortality.

\section{Conflict of Interest}

All the authors do not have any possible conflicts of interest.

\section{Acknowledgements}

The first author would like to thank Supervisors in Pediatric Emergency Division, Department of Child Health, Faculty of 
Medicine Udayana University, for direction and proper guidance in this study.

\section{References}

[1] Tsushima K, King LS, Aggarwal NR, De Gorordo A, D'Alessio FR, Kubo K. Acute lung injury review. Intern Med. 2009; 48: 621-30.

[2] Panico FF, Troster EJ, Oliveira CS, Faria A, Lucena M, Joao PRD, et al. Risk factors for mortality and outcomes in pediatric acute lung injury/acute respiratory distress syndrome. Pediatr Crit Care Med. 2015; 16: 194-200.

[3] Santschi M, Jouvet P, Leclerc F, Gauvin F, Newth CJ, Carroll $\mathrm{CL}$, et al. Acute lung injury in children: therapeutic practice and feasibility of international clinical trials. Pediatr Crit Care Med. 2010; 11: 681-9.

[4] Monahan LJ. Acute respiratory distress syndrome. Curr Probl Pediatr Adolesc Health Care. 2013; 43: 278-84.

[5] Pediatric Acute Lung Injury Consensus Conference Group. Pediatric acute respiratory distress syndrome: consesus recommendations from Pediatric Acute Lung Injury Consensus Conference. Pediatr Crit Care Med. 2015; 16: 428-39.

[6] Sharma BS, Meena HM, Garg V, Sharma P. Acute respiratory distress syndrome in Children: recent perspective. Clin Res Pulmonol. 2017; 5 (2): 1044.

[7] Cheifetz IM. Pediatric acute respiratory distress syndrome. Respiratory Care. 2017; 62 (6): 718-31.

[8] Erickson S, Schibler A, Numa A, Nuthall G, Yung M, Pascoe E, et al. Acute lung injury in pediatric intensive care in Australia and New Zealand-A prospective, multicenter, observational study. Pediatr Crit Care Med. 2007; 8: 317-23.

[9] Zimmerman JJ, Akhtar SR, Caldwell E, Rubenfeld GD. Incidence and outcomes of pediatric acute lung injury. Pediatrics. 2009; 124: 87-95.

[10] Yu WL, Lu ZJ, Wang Y, Shi LP, Kuang FW, Qian SY, et al. Collaborative Study Group of Pediatric Respiratory Failure. The epidemiology of acute respiratory distress syndrome in pediatric intensive care units in China. Intensive Care Med. 2009; 35: 136-43.

[11] Ling Y, Suparyatha IBG. Kadar feritin serum yang tinggi meningkatkan mortalitas penderita acute lung injury dan acute respiratory distress syndrome di Unit Perawatan Intensif Anak. Tesis. Pertemuan Ilmiah Tahunan, Surabaya, 2014.

[12] Rotta AT, Piva JP, Andreolio C, de Carvalho WB, Garcia PCR. Progress and perspectives in pediatric acute respiratory distress syndrome. Rev Bras Ter Intensiva. 2015; 27: 266-73.

[13] Farias JA, Frutos F, Esteban A, Flores JC, Retta A, Baltodano $\mathrm{A}$, et al. What is the daily practice of mechanical ventilation in pediatric intensive care units? A multicenter study. Intensive Care Med. 2004; 30: 918-25.

[14] Lopez-Fernandez Y, de Azagra AM, de la Oliva P, Modesto V, Sanchez JI, Parrilla J, et al. Pediatric Acute Lung Injury Epidemiology and Natural History (PED-ALIEN) Network. Pediatric Acute Lung Injury Epidemiology and Natural History study: Incidence and outcome of the acute respiratory distress syndrome in children. Crit Care Med. 2012; 40: 3238-45.
[15] Gupta S, Sankar J, Lodha R, Kabra SK. Comparison of Prevalence and Outcomes of Pediatric acute respiratory Distress syndrome Using Pediatric acute lung injury consensus conference criteria and Berlin Definition. Front Pediatr. 2018; 6: 93.

[16] Cornfield DN. Acute respiratory distress syndrome in children: physiology and management. Curr Opin Pediatr. 2013; 25: 338-43.

[17] Pelosi P, D'Onofrio D, Chiumello D, Paolo S, Chiara G, Capelozzi VL, et al. Pulmonary and extrapulmonary acute respiratory distress syndrome are different. Eur Respir J Suppl. 2003; 42: 48s-56s.

[18] Menezes SL, Bozza PT, Neto HCCF, Laranjeira AP, Negri EM, Capelozzi VL, et al. Pulmonary and extrapulmonary acute lung injury: Inflammatory and ultrastructural analyses. J Appl Physiol. 2005; 98: 1777-83.

[19] Sapru A, Flori H, Quasney MW, Dahmer MK, Pediatric Acute Lung Injury Consensus Conference Group. Pathobiology of acute respiratory distress syndrome. Pediatr Crit Care Med. 2015; 16 (5): S6-22.

[20] Davis SL, Furman DP, Costarino AT. Acute respiratory distress syndrome in children: Associated disease, clinical course, and predictors of death. J Pediatr. 1993; 123: 35-45.

[21] Luo L, Shaver CM, Zhao Z, Koyama T, Calfee CS, Bastarache JA, et al. Clinical predictors of hospital mortality differ between direct and indirect ARDS. Chest. 2017; 151: 755-63.

[22] Gan CS, Wong JJ, Samransamruajkit R. Differences between pulmonary and extrapulmonary pediatric acute respiratory distress syndrome: a multicenter analysis. Pediatr Crit Care Med. 2018; 20: 1-10.

[23] Zhu YF, Xu F, Lu XL, Wang Y, Chen JL, Chao JX, et al. Mortality and morbidity of acute hypoxemic respiratory failure and acute respiratory distress syndrome in infants and young children. Chin Med J. 2012; 125: 2265-71.

[24] Khemani RG, Smith L, Lopez-Fernandez YM, Kwok J, Morzov R, Klein MJ, et al. Paediatric acute respiratory distress syndrome incidence and epidemiology (PARDIE): an international, observational study. Lancet Respir Med. 2018; 7 (2): $115-28$.

[25] Hu X, Qian S, Xu F, Huang B, Zhou D, Wang Y, et al: Incidence, management and mortality of acute hypoxemic respiratory failure and acute respiratory distress syndrome from a prospective study of Chinese paediatric intensive care network. Acta Paediatr. 2010; 99: 715-21.

[26] Schouten LR, Veltkamp F, Bos AP, van Woensel JB, Serpa Neto A, Schultz MJ, et al. Incidence and mortality of acute respiratory distress syndrome in children: A systematic review and meta-analysis. Crit Care Med. 2016; 44: 819-29.

[27] Wolf GK, Gomez-Laberge C, Kheir JN, Zurakowski D, Walsh BK, Adler A, et al. Reversal of dependent lung collapse predicts response to lung recruitment in children with early acute lung injury. Pediatr Crit Care Med. 2012; 13: 509-15.

[28] Kangelaris KN, Prakash A, Liu KD, Aouizerat B, Woodruff PG, Erle DJ, et al. Increased expression of neutrophil-related genes in patients with early sepsis-induced ARDS. Am J Physiol Lung Cell Mol Physiol. 2015; 308: L1102-13. 
[29] Maniatis NA, Kotanidou A, Catravas JD, Orfanos SE. Endothelial pathomechanisms in acute lung injury. Vascul Pharmacol. 2008; 49: 119-33.

[30] Zinter MS, Orwoll BE, Spicer AC, Alkhouli MF, Calfee CS, Matthay MA, et al. Incorporating inflammation into mortality risk in pediatric acute respiratory distress syndrome. Crit Care Med. 2017; 45: 858-66.
[31] Gattinoni L, Chiumello D, Carlesso E, Valenza F. Bench-to-bedside review: Chest wall elastance in acute lung injury/acute respiratory distress syndrome patients. Crit Care. 2004; 8: 350-5.

[32] Sehgal IS, Dhooria S, Behera D, Agarwal R. Acute respiratory distress syndrome: Pulmonary and extrapulmonary not so similar. Indian J Crit Care Med. 2016; 20: 194-7. 